\title{
The antioxidant icariin protects porcine oocytes from age-related damage in vitro
}

\author{
Jae-Wook Yoon ${ }^{1,2, a}$, Seung-Eun Lee, ${ }^{1,2, a}$, Yun-Gwi Park ${ }^{1,2}$, Won-Jae Kim ${ }^{1,2}$, Hyo-Jin Park ${ }^{1,2}$, \\ Chan-Oh Park ${ }^{1,2}$, So-Hee Kim ${ }^{1,2}$, Seung-Hwan Oh ${ }^{1,2}$, Do-Geon Lee ${ }^{1,2}$, Da-Bin Pyeon ${ }^{1,2}$, \\ Eun-Young Kim ${ }^{1,2,3}$, and Se-Pill Park ${ }^{1,2,3, *}$
}

\footnotetext{
* Corresponding Author: Se-Pill Park Tel: +82-64-754-4650,

Fax: +82-0303-3130-4650,

E-mail:sppark@jejunu.ac.kr
}

${ }^{1}$ Faculty of Biotechnology, College of Applied Life Sciences, Jeju National University, Jeju 63243, Korea

2 Stem Cell Research Center, Jeju National

University, Jeju 63243, Korea

${ }^{3}$ Mirae Cell Bio, Seoul 04795, Korea

a These authors contributed equally to this work.

ORCID

Jae-Wook Yoon

https://orcid org/0000-0001-7417-6963

Seung-Eun Lee

https://orcid.org/0000-0001-6128-8560 Yun-Gwi Park

https://orcid.org/0000-0002-7139-7637 Won-Jae Kim

https://orcid.org/0000-0002-4253-9202

Hyo-Jin Park

https://orcid.org/0000-0002-1778-5866 Chan-Oh Park

https://orcid.org/0000-0001-5654-0207 So-Hee Kim

https://orcid.org/0000-0003-3361-1361

Seung-Hwan Oh

https://orcid org/0000-0003-0829-0711

Do-Geon Lee

https://orcid.org/0000-0003-3893-6288 Da-Bin Pyeon

https://orcid.org/0000-0001-6443-2273

Eun-Young Kim

https://orcid.org/0000-0001-6299-6876

Se-Pill Park

https://orcid.org/0000-0002-6965-7831

Submitted Jan 28, 2020; Revised Feb 26, 2020; Accepted Apr 29, 2020
Objective: If fertilization does not occur within a specific period, the quality of unfertilized oocytes in the oviduct (in vivo aging) or in culture (in vitro aging) will deteriorate over time. Icariin (ICA), found in all species of Epimedium herbs, has strong antioxidant activity, and is thought to exert anti-aging effects in vitro. We asked whether ICA protects oocytes against age-related changes in vitro.

Methods: We analyzed the reactive oxygen species (ROS) levels and expression of antioxidant, maternal, and estrogen receptor genes, and along with spindle morphology, and the developmental competence and quality of embryos in the presence and absence of ICA.

Results: Treatment with $5 \mu \mathrm{M}$ ICA (ICA-5) led to a significant reduction in ROS activity, but increased mRNA expression of glutathione and antioxidant genes (superoxide dismutase 1 [SOD1], SOD2, peroxiredoxin 5, and nuclear factor erythroid 2-like 2), during aging in vitro. In addition, ICA- 5 prevented defects in spindle formation and chromosomal alignment, and increased mRNA expression of cytoplasmic maturation factor genes (bone morphogenetic protein 15 , cyclin $\mathrm{B} 1, \mathrm{MOS}$ proto-oncogene, serine/threonine kinase, and growth differentiation factor-9). It also prevented apoptosis, increased mRNA expression of antiapoptotic genes (BCL2-like 1 and baculoviral IAP repeat-containing 5), and reduced mRNA expression of pro-apoptotic genes (BCL2 antagonist/killer 1 and activation of caspase-3). Although the maturation and cleavage rates were similar in all groups, the total cell number per blastocyst and the percentage of apoptotic cells at the blastocyst stage were higher and lower, respectively, in the control and ICA-5 groups than in the aging group.

Conclusion: ICA protects oocytes against damage during aging in vitro; therefore, it can be used to improve assisted reproductive technologies.

Keywords: In vitro Aging; Porcine; Oocyte; Icariin; Antioxidant

\section{INTRODUCTION}

In vitro production technologies of embryos comprise three major successive stages: in vitro maturation (IVM) of immature oocytes, in vitro fertilization (IVF), and in vitro culture (IVC) of fertilized oocytes. The quality of mature oocytes in vitro determines the success of assisted reproductive technologies in mammalian species. In porcine in vitro production systems, immature oocytes are usually obtained from antral follicles (measuring 2 to $8 \mathrm{~mm}$ in diameter) in ovaries collected from a local slaughterhouse. Meiosis resumes spontaneously during culture of immature mammalian oocytes following removal from follicles. These oocytes undergo germinal vesicle breakdown after 16 to $20 \mathrm{~h}$ and reach metaphase of the second meiotic division (MII) by $40 \mathrm{~h}$; then, meiosis arrests again until fertilization occurs. The nuclear and cytoplasmic events that occur during this process are referred to 
collectively as maturation and are required for monospermic fertilization and early embryonic development [1]. If fertilization does not occur within a specific period of time, the quality of unfertilized oocytes in the oviduct (in vivo aging) or in culture (in vitro aging) will deteriorate over time. The aging of oocytes is one of the factors limiting the results of various assisted reproductive technology in several mammalian species [2]. Several studies report that post-ovulatory aging correlates strongly with various oocyte defects, including zona pellucida hardening, spindle and chromosomal abnormalities, reduced capability for fertilization, abnormal development of embryos and fetuses, mitochondrial alterations, and changes in gene and protein expression $[3,4]$. In addition, post-ovulatory aging is accompanied by varied molecular, cellular, and biochemical changes, including mitochondria dysfunction, production of reactive oxygen species (ROS), decreased activity of maturation-promoting factors, decreased expression of the anti-apoptotic factor B-cell lymphoma 2 (BCL-2), activation of caspase-3 (CASP3), and changes in epigenetic modifications [2]. These deleterious aging-induced changes can reduce the quality of oocyte and adversely affect fertilization, and subsequent development of embryo. Therefore, many researchers have sought to develop methods that protect oocytes against in vitro aging.

The flavonoid icariin (ICA) is present in all species of Epimedium herbs and is extracted from the stem and leaves of the traditional Chinese medicinal plant Epimedium brevicornum Maxim (Herba Epimedii; family Berberidacae). ICA has a broad range of biological and pharmacological properties properties, including antioxidant and anti-inflammatory [5]. In addition, other studies have suggested that ICA acts as a phytoestrogen involved in activation of the estrogen receptor signaling pathway or cooperates with the estrogenestrogen receptor complex in the nucleus [6].

We investigated the antioxidant effects of various concentrations of ICA during aging of porcine oocytes in vitro. We analyzed spindle morphology, levels of ROS, expression of antioxidant, estrogen receptor, and maternal genes in aged porcine oocytes treated with or without ICA. It also determined the developmental capacity and quality of embryos produced through parthenogenesis of these oocytes. The results show that ICA protects porcine oocytes against damage during aging in vitro by preventing oxidative stress. These findings may be applicable to aging during the IVM and help to protect oocytes against aging.

\section{MATERIALS AND METHODS}

\section{Chemicals and reagents}

All chemicals and reagents were purchased from Sigma (St. Louis, MO, USA) unless stated otherwise.
Aging and in vitro maturation of porcine oocytes Prepubertal porcine ovaries were collected from a local slaughterhouse and transported (within $2 \mathrm{~h}$ ) at $30^{\circ} \mathrm{C}$ to $33^{\circ} \mathrm{C}$ to the laboratory in saline supplemented with $75 \mu \mathrm{g} / \mathrm{mL}$ penicillin $\mathrm{G}$ and $50 \mu \mathrm{g} / \mathrm{mL}$ streptomycin sulfate. Cumulus-oocyte complexes (COCs) were aspirated from follicles with a diameter of 2 to $8 \mathrm{~mm}$ using an 18-gauge needle and a disposable 10 $\mathrm{mL}$ syringe. COCs were washed three times in tissue culture medium (TCM)-199-HEPES containing $0.1 \%(\mathrm{w} / \mathrm{v})$ bovine serum albumin (BSA). Thereafter, COCs (groups of 50 to 60 ) were matured in $500 \mu \mathrm{L}$ TCM-199 (Gibco, Grand Island, NY, USA) containing Earle's salts, $0.57 \mathrm{mM}$ cysteine, $10 \mathrm{ng} / \mathrm{mL}$ epidermal growth factor, $0.5 \mu \mathrm{g} / \mathrm{mL}$ follicle-stimulating hormone, $0.5 \mu \mathrm{g} / \mathrm{mL}$ luteinizing hormone, and $10 \%$ $(\mathrm{v} / \mathrm{v})$ porcine follicular fluid under mineral oil for $44 \mathrm{~h}$ (control) at $38.8^{\circ} \mathrm{C} / 5 \% \mathrm{CO}_{2}$ in air. Oocyte aging was induced by culturing COCs for an additional $24 \mathrm{~h}$ (total of $68 \mathrm{~h})(0,5$, 50 , or $500 \mu \mathrm{M}$ ICA) in TCM-199.

\section{Oocyte aging and icariin treatment}

Mature oocytes were covered with mineral oil and cultured at $38.8^{\circ} \mathrm{C}$ in a humidified atmosphere of $5 \% \mathrm{CO}_{2}$ in air in a 4-well dish containing $500 \mu \mathrm{L}$ TCM-199. After maturation, MII oocytes were transferred to TCM-199 containing 0, 5, 50 , or $500 \mu \mathrm{M}$ ICA and cultured for an additional $24 \mathrm{~h}$ (total of $68 \mathrm{~h}$ ) as described above. After treatment, oocytes were collected and aging was assessed.

\section{Parthenogenetic activation and embryo culture}

We conducted parthenogenesis rather than IVF or intracytoplasmic sperm injection (ICSI). Before implantation, parthenogenesis can reveal the outcome (roughly) of IVF or ICSI. The results are not exact, but an approximate pattern can be determined.

Porcine oocytes mature after $44 \mathrm{~h}$ (control) or for an additional $24 \mathrm{~h}$ ( $68 \mathrm{~h}$ total) $(0,5,50$, or $500 \mu \mathrm{M}$ ICA), cumulus cells were removed by pipetting for 2 to $3 \mathrm{~min}$ in the presence of $1 \mathrm{mg} / \mathrm{mL}$ hyaluronidase. Parthenogenetic activation (PA) was induced by treating oocytes for $5 \mathrm{~min}$ with porcine zygote medium- 5 containing $0.4 \%(\mathrm{w} / \mathrm{v}) \mathrm{BSA}$ (IVC medium) and 5 $\mu \mathrm{M} \mathrm{Ca}^{2+}$ ionomycin. After $3 \mathrm{~h}$ of culture in IVC medium containing $7.5 \mu \mathrm{g} / \mathrm{mL}$ cytochalasin $\mathrm{B}$, embryos were washed three times in the IVC medium and cultured for 7 days at $38.8^{\circ} \mathrm{C}$ in a humidified atmosphere of $5 \% \mathrm{CO}_{2}$ and $95 \%$ air. Oocytes and embryos were washed in Dulbecco's phosphate-buffered saline (DPBS) and either fixed in 3.7\% (w/v) paraformaldehyde for $20 \mathrm{~min}$ and stored at $4^{\circ} \mathrm{C}$, or snap-frozen in liquid nitrogen and stored at $-80^{\circ} \mathrm{C}$, depending on the experiment.

Measurement of intracellular reactive oxygen species and glutathione levels

Dichlorohydrofluorescein diacetate (DCFHDA) and Cell- 
Tracker Blue 4-chloromethyl-6,8-difluoro-7-hydroxycoumarin $\left(\mathrm{CMF}_{2} \mathrm{HC}\right)$ were used to determine the intracellular levels of ROS and glutathione (GSH), respectively, as previously described $[7,8]$, with slight modifications. Briefly, porcine oocytes mature after $44 \mathrm{~h}$ (control) or for an additional $24 \mathrm{~h}$ ( $68 \mathrm{~h}$ total) (0 and $5 \mu \mathrm{M}$ ICA), cumulus cells were removed from COCs by pipetting in the presence of $0.1 \%(\mathrm{w} / \mathrm{v})$ hyaluronidase. Denuded oocytes were incubated in the dark for $20 \mathrm{~min}$ at $38.8^{\circ} \mathrm{C}$ in DPBS containing $50 \mu \mathrm{M}$ DCFHDA or $100 \mu \mathrm{M}$ $\mathrm{CMF}_{2} \mathrm{HC}$. Thereafter, oocytes were washed more than five times with DPBS containing $0.1 \%(\mathrm{w} / \mathrm{v}$ ) BSA to completely remove excess dye and analyzed immediately by epifluorescence microscopy (Olympus, Tokyo, Japan). The ROS level was measured at excitation and emission wavelengths of 450 to $490 \mathrm{~nm}$ and 515 to $565 \mathrm{~nm}$, respectively. The excitation and emission wavelengths of $\mathrm{CMF}_{2} \mathrm{HC}$ are 371 and $464 \mathrm{~nm}$, respectively. Grayscale images were acquired with a digital camera (Nikon, Tokyo, Japan) attached to the microscope, and mean grayscale values were calculated using ImageJ software (NIH, Bethesda, MD, USA). Background fluorescence values were subtracted from the final values before statistical analysis. The replicate was repeated independently 6 to 7 times using 20 to 30 oocytes per experiment.

\section{Immunofluorescence analysis}

Oocyte meiotic spindles and nuclei were visualized after maturation. Cumulus cells were removed from porcine COCs matured for $44 \mathrm{~h}$ (control) or an additional $24 \mathrm{~h}$ (total of $68 \mathrm{~h})(0$ and $5 \mu \mathrm{M}$ ICA), and then oocytes were fixed overnight at $4^{\circ} \mathrm{C}$ in $4.0 \%(\mathrm{w} / \mathrm{v})$ paraformaldehyde prepared in phosphate-buffered saline (PBS). Fixed oocytes were incubated in $0.5 \%(\mathrm{v} / \mathrm{v})$ Triton X-100 for $30 \mathrm{~min}$ at $38.8^{\circ} \mathrm{C}$. After blocking for $1 \mathrm{~h}$ with $1 \%$ BSA (w/v) prepared in PBS (blocking solution I), oocytes were incubated overnight at $4^{\circ} \mathrm{C}$ with a fluorescein isothiocyanate-conjugated anti- $\alpha$-tubulin antibody (diluted 1:200 in blocking solution I). Nuclei were stained for $30 \mathrm{~min}$ with Hoechst $33342(1 \mu \mathrm{g} / \mathrm{mL})$. Finally, oocytes were washed three times with PBS containing $0.1 \%$ $(\mathrm{w} / \mathrm{v})$ BSA, mounted on glass slides, and observed under an inverted Olympus IX-71 microscope. To further investigate the effect of ICA on spindle organization, spindles without any abnormalities were classified as normal, whereas those in which chromosomes failed to align at the metaphase plate were classified as abnormal. Each experiment was repeated independently three times, and at least 20 oocytes were examined per group.

Terminal deoxynucleotidyl transferase dUTP nick-end labeling and Hoechst staining

Porcine oocytes matured for $44 \mathrm{~h}$ (control) or an additional $24 \mathrm{~h}$ (total, $68 \mathrm{~h})(0$ and $5 \mu \mathrm{M}$ ICA). At 7 days post-PA, blastocysts were fixed overnight at $4^{\circ} \mathrm{C}$ with $4.0 \%(\mathrm{w} / \mathrm{v})$ para- formaldehyde prepared in PBS, washed more than three times with PBS containing 0.1\% BSA, and then incubated at $38.8^{\circ} \mathrm{C}$ for $30 \mathrm{~min}$ with $0.1 \%$ Triton X-100. Blastocysts were incubated in the dark for $1 \mathrm{~h}$ at $38.8^{\circ} \mathrm{C}$ with fluoresceinconjugated dUTP and terminal deoxynucleotidyl transferase (In Situ Cell Death Detection Kit; Roche, Manheim, Germany). Mitotic and apoptotic cells were scored. Nuclei were stained for $30 \mathrm{~min}$ with Hoechst $33342(1 \mu \mathrm{g} / \mathrm{mL})$ and embryos were washed with PBS containing $0.1 \%$ BSA. Blastocysts were mounted on glass slides and examined under an inverted Olympus IX-71 fluorescence microscope. The experiment was repeated independently 3 to 4 times; at least 10 to 20 blastocysts were examined per group.

\section{Extraction of mRNA and synthesis of complementary DNA}

First, mRNA was isolated from more than three biological replicates (30 to 40 oocytes per replicate) using a Dynabeads mRNA Direct Kit (Invitrogen, Carlsbad, CA, USA) according to the manufacturer's instructions. Next, mRNA was collected in $10 \mu \mathrm{L}$ elution buffer (provided with the kit). Eluted RNA was reverse-transcribed into complementary DNA using an oligo (dT) 20 primer and SuperScript II reverse transcriptase (Invitrogen, USA), according to the manufacturer's instructions.

\section{Real-time reverse transcription polymerase chain reaction}

The protocol used was the same as that described previously [9]. Real-time reverse transcription polymerase chain reaction (RT-PCR) was performed using the primer sets listed in Table 1 and a StepOnePlus Real-time PCR System (Applied Biosystems, Warrington, UK) in a final reaction volume of $20 \mu \mathrm{L}$ containing SYBR Green PCR Master Mix (Applied Biosystems, UK). The PCR conditions were as follows: $10 \mathrm{~min}$ at $95^{\circ} \mathrm{C}$, followed by 39 cycles of $15 \mathrm{~s}$ at $95^{\circ} \mathrm{C}$ and $60 \mathrm{~s}$ at $54^{\circ} \mathrm{C}$ or $60^{\circ} \mathrm{C}$. Samples were then cooled to $12^{\circ} \mathrm{C}$. Relative gene expression was analyzed using the $2^{-\Delta \Delta \mathrm{Ct}}$ method [10] after normalization against expression of a housekeeping gene (maternal genes, estrogen receptor genes and apoptosis-related genes: glyceraldehyde-3-phosphate dehydrogenase; and antioxidant genes: $\beta$-actin). The experiment was repeated independently five times.

\section{Western blot analysis}

The protocol was the same as that described previously [9]. In brief, oocytes ( 40 per sample) were solubilized in $20 \mu \mathrm{L}$ of $1 \times$ sodium dodecyl sulfate (SDS) sample buffer $(62.5 \mathrm{mM}$ Tris- $\mathrm{HCl}$, pH 6.8, containing $2 \%(\mathrm{w} / \mathrm{v})$ SDS, $10 \%$ (v/v) glycerol, $50 \mu \mathrm{M}$ dithiothreitol, and $0.01 \%(\mathrm{w} / \mathrm{v})$ bromophenol blue or phenol red) and heated for $5 \mathrm{~min}$ at $95^{\circ} \mathrm{C}$. Proteins were resolved for $1.5 \mathrm{~h}$ at 80 to $100 \mathrm{~V}$ on $5 \%$ to $12 \%$ Tris SDS- 
Table 1. Primers used for real-time reverse transcription polymerase chain reaction

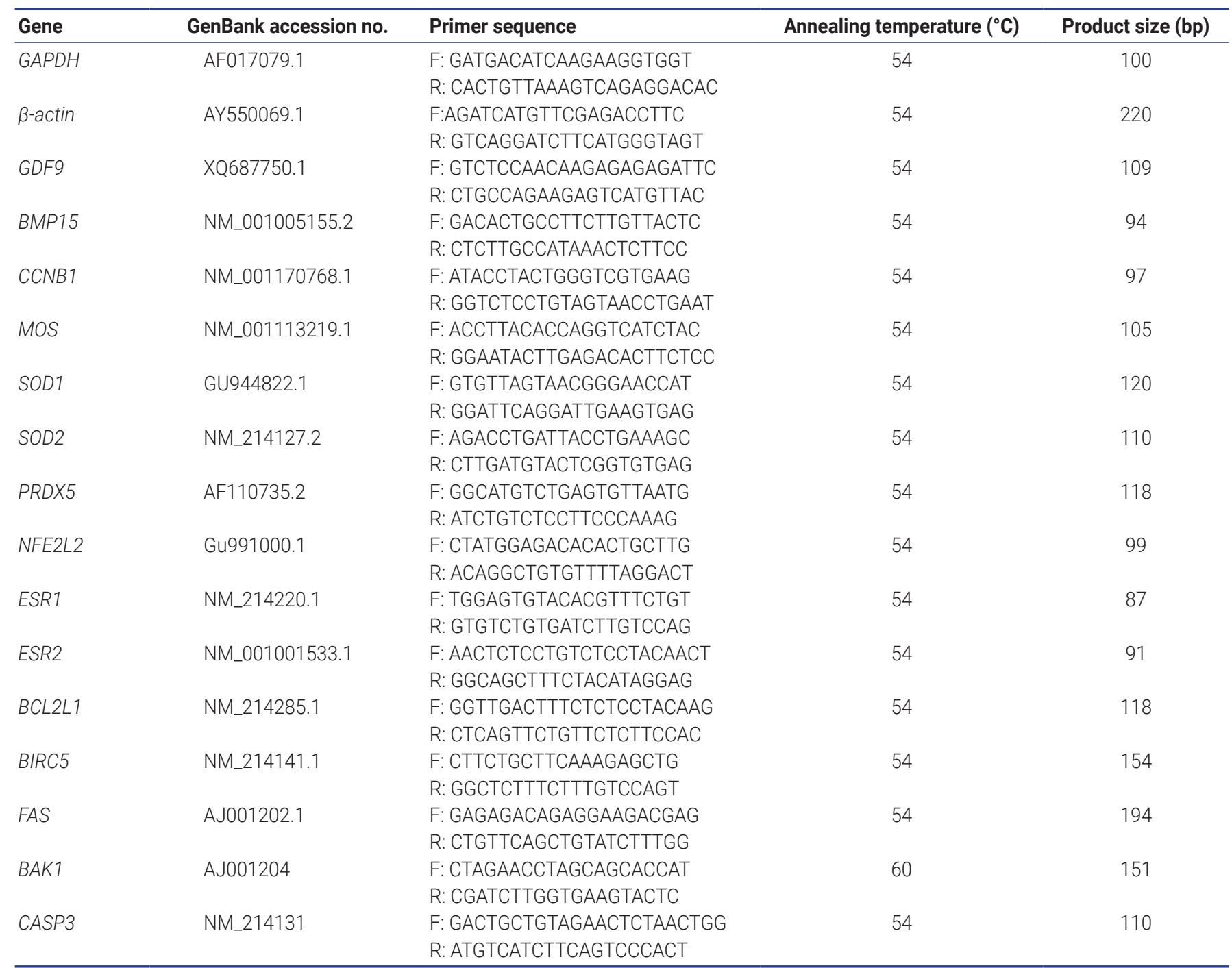

F, forward; R, reverse; GAPDH, glyceraldehyde-3-phosphate dehydrogenase; GDF9, growth differentiation factor-9; BMP15, bone morphogenetic protein 15; CCNB1, cyclin B1; MOS, MOS proto-oncogene, serine/threonine kinase; SOD1, superoxide dismutase 1; SOD2, superoxide dismutase 2; PRDX5, peroxiredoxin 5; NFE2L2, nuclear factor erythroid 2-like 2; ESR1, estrogen receptor 1; ESR2, estrogen receptor 2; BCL2L1, BCL2-like 1; BIRC5, baculoviral IAP repeat-containing 5; FAS, Fas cell surface death receptor; BAK1, BCL2 antagonist/killer 1; CASP3, caspase-3.

polyacrylamide gel electrophoresis gels. Samples were then transferred to Hybond-ECL nitrocellulose membranes (Amersham, Buckinghamshire, UK) at $300 \mathrm{~mA}$ for $2 \mathrm{~h}$ in transfer buffer (25 mM Tris, $\mathrm{pH} 8.5$, containing $200 \mathrm{mM}$ glycine and $20 \%[\mathrm{v} / \mathrm{v}]$ methanol). After blocking for $1 \mathrm{~h}$ with $5 \%(\mathrm{w} / \mathrm{v})$ nonfat milk prepared in PBS, the membranes were incubated for at least $2 \mathrm{~h}$ with an anti-p44/42 MAPK or anti-phosphop44/42 MAPK antibody diluted 1:500 in blocking solution ( $1 \times$ Tris-buffered saline, $\mathrm{pH} 7.5$, containing $0.1 \%[\mathrm{v} / \mathrm{v}]$ Tween-20\% and 5\% [w/v] nonfat milk). Thereafter, the membranes were washed three times in TBST $(20 \mathrm{mM}$ Tris- $\mathrm{HCl}$, $\mathrm{pH} 7.5$, containing $250 \mathrm{mM} \mathrm{NaCl}$ and $0.1 \%$ [v/v] Tween-20) and incubated for $1 \mathrm{~h}$ with anti-rabbit immunoglobulin Ghorseradish peroxidase diluted 1:2,000 in blocking solution. After three washes with TBST, immunoreactive protein bands were visualized in a dark room using X-ray films and a chemiluminescent luminol reagent (Invitrogen, USA). The amount of protein based on the band densities was calculated using ImageJ software (NIH, USA). The experiment was repeated independently three times.

\section{Statistical analysis}

The general linear model procedure within the Statistical Analysis System (SAS User's Guide, 1985, Statistical Analysis System Inc., Cary, NC, USA) was used to analyze data from all experiments. The paired Tukey's multiple range test were used to determine significant differences. Statistical significance is defined when $p$ values are less than 0.05 . 


\section{RESULTS}

Icariin enhances the embryo development of aging porcine oocytes in vitro

Porcine oocytes were matured in vitro for $44 \mathrm{~h}$ (control) or an additional $24 \mathrm{~h}$ (total, $68 \mathrm{~h}$ ) in the presence of $0,5,50$, or $500 \mu \mathrm{M}$ ICA (referred to as aging, ICA-5, ICA-50, and ICA500 , respectively) to determine the optimal concentration. There was no difference between the groups in the rate of MII reach of porcine oocytes. The percentage of oocytes that reached the 2 to 4-cell stage through cleavage after PA did not differ between the aging, ICA-5, ICA-50, ICA-500, and control groups (Table 2). The rate of blastocyst development at day 7 of cleaved oocytes was significantly higher $(\mathrm{p}<0.05)$ in the control and ICA-treated groups than in the aging group; the percentages between the ICA-5, ICA-50, and ICA-500 groups were similar (Table 2). Therefore, we compared the control, aging, and ICA-5 groups in subsequent experiments. The replicate was repeated seven independent times, with 50 to 60 oocytes per experiment.

Icariin reduces the level of reactive oxygen species in aging porcine oocytes in vitro

At the MII stage, the effects of ICA on ROS and GSH levels were analyzed by staining oocytes with DCFHDA and $\mathrm{CMF}_{2} \mathrm{HC}$, respectively (Figure $1 \mathrm{~A}$ ). ROS levels in the ICA5 group were significantly lower $(\mathrm{p}<0.05)$ than those in the aging group, but there was no difference between the control and aging groups (control, $1.0 \pm 0.0$ pixels/oocyte; aging, $1.0 \pm 0.0$ pixels/oocyte; and ICA-5, $0.8 \pm 0.1$ pixels/oocyte; Figure $1 \mathrm{~B})$. The staining intensity of GSH was significantly higher $(\mathrm{p}<0.05)$ in the control and ICA-5 groups than in the aging group (control, $1.0 \pm 0.0$ pixels/oocyte; aging, $0.8 \pm$ 0.1 pixels/oocyte; and ICA-5, $1.1 \pm 0.1$ pixels/oocyte; Figure $1 \mathrm{C})$.

Expression of the antioxidant genes superoxide dismutase 1 (SOD1), superoxide dismutase 2 (SOD2), peroxiredoxin 5 (PRDX5), and nuclear factor erythroid 2-like 2 (NFE2L2) was analyzed by real-time RT-PCR (Figure 1D). mRNA expression of SOD1 and PRDX5 was significantly higher ( $\mathrm{p}<$ 0.05 ) in the ICA-5 group than in the aging group, and was similar in the control and aging groups. mRNA expression of $S O D 2$ was significantly higher $(\mathrm{p}<0.05)$ in the ICA-5 group than in the aging group, but similar to that in the control group. mRNA expression of NFE2L2 was significantly higher $(\mathrm{p}<0.05)$ in the ICA-5 group than in the aging and control groups.

Icariin prevents chromosome misalignment and abnormal spindle organization in aging porcine oocytes in vitro

The percentage of oocytes with normal meiotic spindles at stage MII was significantly higher $(\mathrm{p}<0.05)$ in the ICA- 5 group than in the aging group, but was similar in the control and ICA-5 groups (control, $80.3 \% \pm 0.8 \%$; aging, $72.6 \% \pm 2.1 \%$; and ICA-5, $86.7 \% \pm 4.5 \%$; Figure 2 ).

Icariin increases the expression of cytoplasmic maturation markers in porcine oocytes during aging in vitro

In order to investigate the effect of ICA on cytoplasmic maturation of aging oocytes in the MII stage, the expression of maternal genes and MAPK activity werw examined (Figure $3)$. Expression of the cytoplasmic maturation marker genes bone morphogenetic protein 15 (BMP15), cyclin B1 (CCNB1), MOS proto-oncogene, serine/threonine kinase (MOS), and growth differentiation factor-9 (GDF9) was analyzed by realtime RT-PCR (Figure 3A). Expression of mRNA encoding $C C N B 1, M O S$, and GDF9 was significantly higher $(\mathrm{p}<0.05)$ in the ICA- 5 group than in the aging group, but significantly lower $(\mathrm{p}<0.05)$ than in the control group. mRNA expression of $B M P 15$ was significantly higher $(\mathrm{p}<0.05)$ in the ICA-5 group than in the aging and control groups. Western blotting has shown that the active form of this kinase, phosphorylated p44/42 MAPK (phospho-p44/42 MAPK), migrated as a doublet in lysates of matured and aged porcine oocytes. The

Table 2. Effect of icariin treatment on subsequent embryo development by porcine oocytes during aging in vitro

\begin{tabular}{|c|c|c|c|c|c|}
\hline Treatment group & $\begin{array}{l}\text { ICA concentration } \\
(\mu \mathrm{M})\end{array}$ & $\begin{array}{l}\text { No. of germinal } \\
\text { vesicle oocytes }\end{array}$ & $\begin{array}{l}\text { No. (\%) of surviving } \\
\text { oocytes }{ }^{1)}\end{array}$ & $\begin{array}{l}\text { No. (\%) of cleaved } \\
\text { oocytes on day } 2^{2)}\end{array}$ & $\begin{array}{c}\text { No. (\%) of blastocysts } \\
\text { on day } 7^{3)}\end{array}$ \\
\hline Control & 0 & 56 & $51(91.4 \pm 1.6)$ & $37(72.8 \pm 5.6)$ & $17(45.8 \pm 3.2)^{c}$ \\
\hline Aging & 0 & 56 & $51(89.8 \pm 1.6)$ & $41(80.2 \pm 5.0)$ & $9(22.9 \pm 1.9)^{a}$ \\
\hline ICA-5 & 5 & 56 & $52(92.0 \pm 0.8)$ & $45(86.0 \pm 4.7)$ & $16(34.8 \pm 2.3)^{b c}$ \\
\hline ICA-50 & 50 & 59 & $54(91.5 \pm 2.9)$ & $42(77.7 \pm 3.7)$ & $15(36.8 \pm 4.8)^{b}$ \\
\hline ICA-500 & 500 & 59 & $53(90.5 \pm 1.7)$ & $42(81.6 \pm 4.1)$ & $16(37.8 \pm 2.3)^{b}$ \\
\hline
\end{tabular}

Values represent the mean \pm standard error of the mean of independent experiments.

ICA, icariin.

1) Percentage of oocytes that reached MII.

2) Percentage of oocytes that underwent cleavage.

3) Percentage of cleaved oocytes that reached the blastocyst stage on day 7

${ }^{a-c}$ Values within the same column with different superscript letters are significantly different $(p<0.05)$. 
A

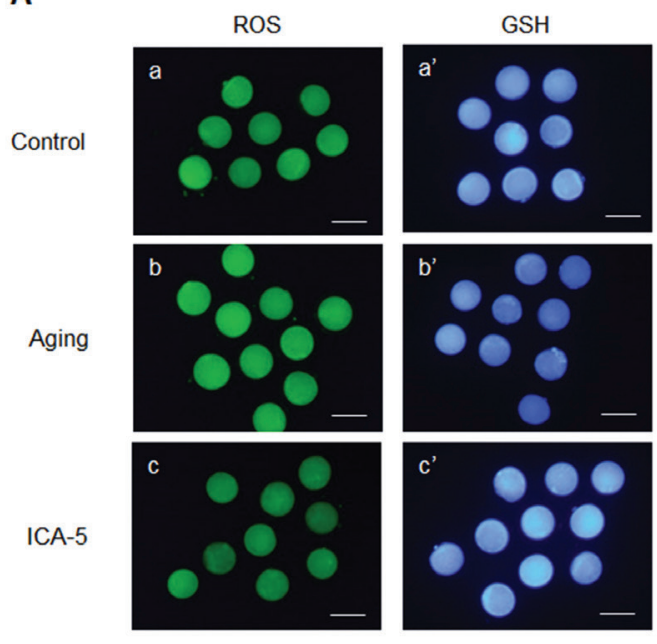

B
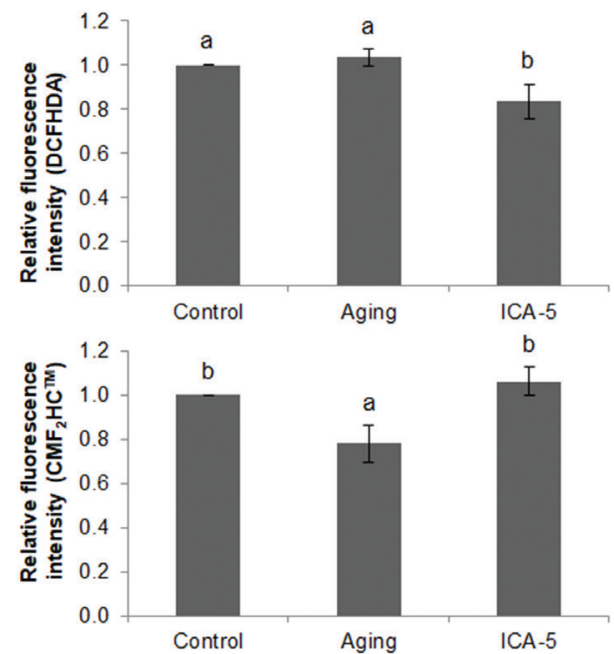

C

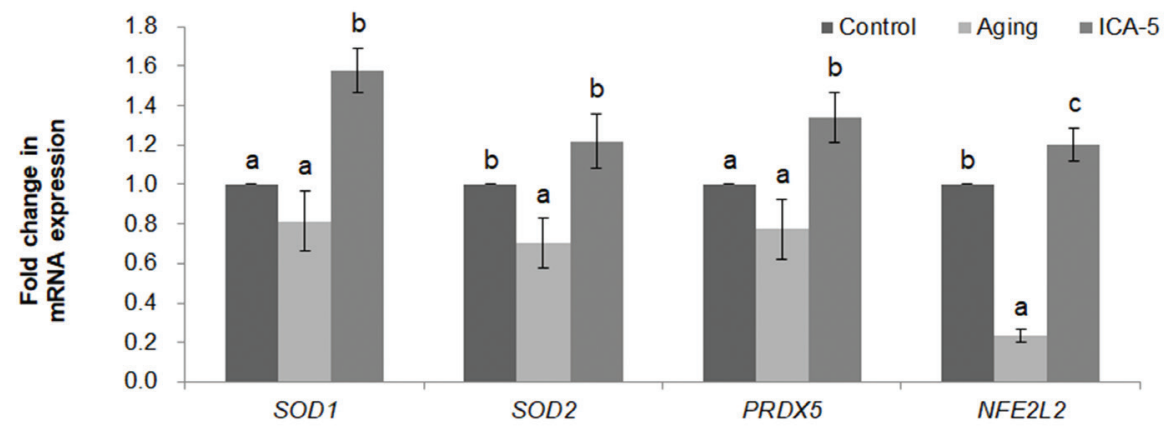

Figure 1. Antioxidant effect of icariin (ICA) during aging of porcine oocytes in vitro. (A) Epifluorescence images of oocytes stained with DCHFDA (green) and CellTracker Blue $\mathrm{CMF}_{2} \mathrm{HC}$ (blue). a and a': control group; b and b': aging group; and c and c': ICA-5 group. a, b, and c: ROS staining; a', b', and c': GSH staining. (B) Fluorescence intensity of intracellular ROS staining. (C) Fluorescence intensity of intracellular GSH staining. (D) Relative expression of antioxidant genes SOD1, SOD2, PRDX5, and NFE2L2. Data are derived from 3 to 4 independent replicates per group are expressed as the mean \pm standard error of the mean. ${ }^{\mathrm{a}-\mathrm{c}} \mathrm{p}<0.05$. Scale bar $=120 \mu \mathrm{m}$. GSH, glutathione; ROS, reactive oxygen species; SOD1, superoxide dismutase 1; SOD2, superoxide dismutase 2; PRDX5, peroxiredoxin 5; NFE2L2, nuclear factor erythroid 2-like 2.

relative ratio of phospho-p44/42 MAPK to total p44/42 MAPK did not differ significantly $(\mathrm{p}<0.05)$ between the groups (control, 1.0 \pm 0.0 ; aging, 0.9 \pm 0.1 ; and ICA-5, 1.0 \pm 0.1 ; Figure 3B).

\section{Icariin increases the expression of estrogen receptor} genes in porcine oocytes during aging in vitro

At the MII stage, the effects of ICA on mRNA expression of estrogen receptor 1 (ESR1) and 2 (ESR2) were analyzed by real-time RT-PCR to determine whether ICA activates these receptors. mRNA expression of ESR1 was significantly higher $(\mathrm{p}<0.05)$ in the ICA-5 group than in the aging group, but it was significantly lower $(\mathrm{p}<0.05)$ than in the control group (Figure 4). mRNA expression of ESR2 was significantly higher $(\mathrm{p}<0.05)$ in the ICA-5 group than in the control and aging groups (Figure 4).

Icariin alters expression of apoptosis-related genes in porcine oocytes during aging in vitro

At the blastocyst stage, expression of apoptosis-related genes BCL2-like 1 (BCL2L1), baculoviral IAP repeat-containing 5
(BIRC5), Fas cell surface death receptor (FAS), BCL2 antagonist/killer 1 (BAK1), and CASP3 was analyzed by real-time RT-PCR (Figure 5). mRNA expression of BCL2L1 was significantly higher $(\mathrm{p}<0.05)$ in the ICA- 5 group than in the control and aging groups, whereas expression of that BIRC5 was significantly higher $(\mathrm{p}<0.05)$ in the ICA-5 group than in the aging group; however, it was similar in the control and ICA-5 groups. Expression of FAS was significantly higher $(\mathrm{p}<0.05)$ in the aging group than in the control group, was similar in the control and ICA-5 groups, and was not significantly different between the aging and ICA- 5 groups. mRNA expression of $B A K 1$ and $C A S P 3$ was significantly higher $(\mathrm{p}<0.05)$ in the ICA-5 group than in the control groups, but significantly lower $(\mathrm{p}<0.05)$ than in the aging group.

\section{Icariin improves the quality and developmental} capacity of embryos derived from aged porcine oocytes in vitro

To investigate whether ICA treatment during IVM of oocytes affects subsequent embryo quality and development, 


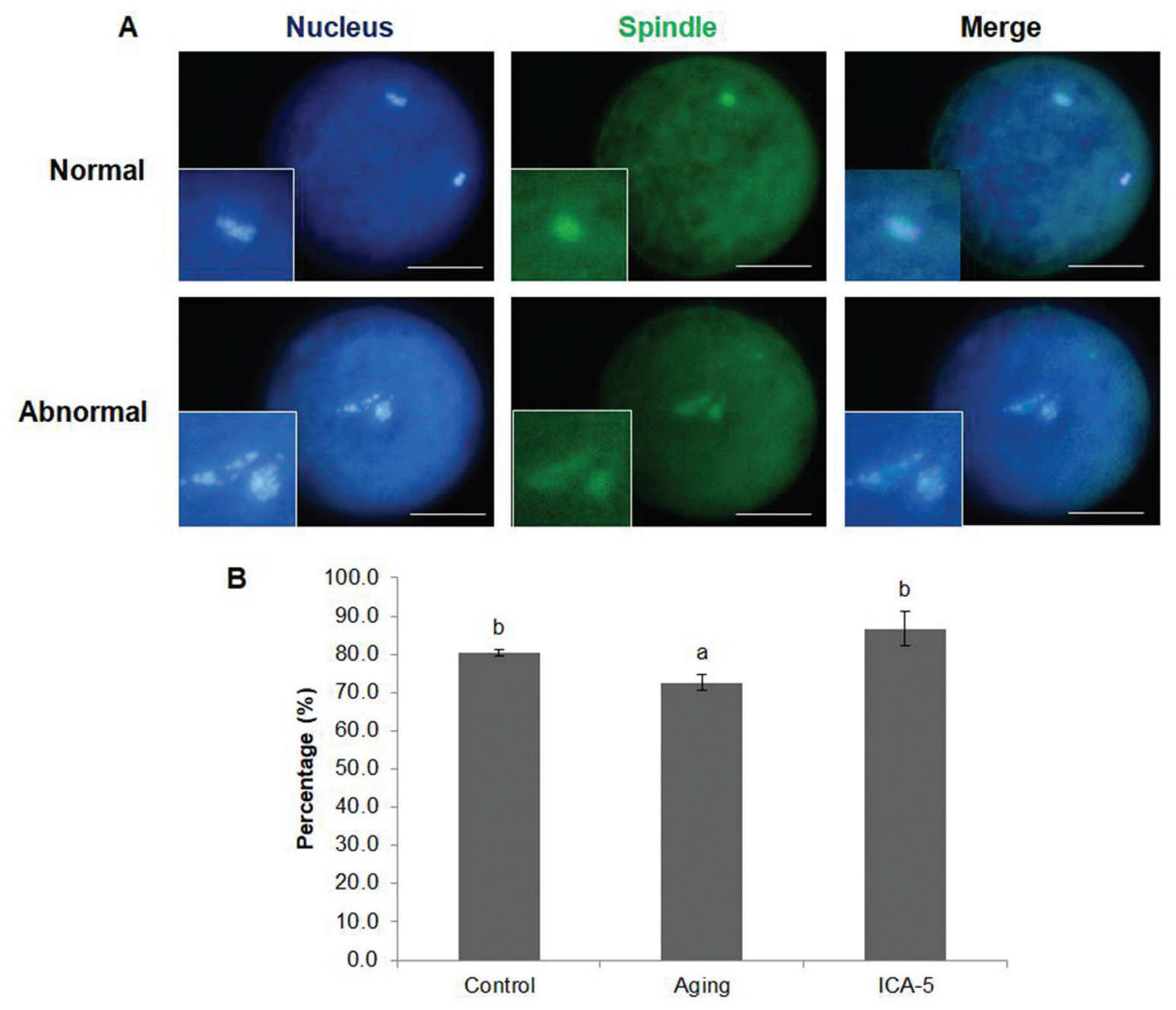

Figure 2. Effect of icariin (ICA) on meiotic spindle morphology in porcine oocytes during aging in vitro. (A) Normal and abnormal chromosome alignment and meiotic spindle formation in oocytes. (B) Percentage of oocytes in which the morphology of the chromosomes and the meiotic spindle were normal. Data are derived from three independent replicates per group and expressed as the mean \pm standard error of the mean (a,b $\mathrm{p}<0.05)$. Scale bar $=50 \mu \mathrm{m}$.

we matured oocytes in the treated with or without of $5 \mu \mathrm{M}$ ICA and then subjected them to PA. The total number of cells per blastocyst was significantly lower $(\mathrm{p}<0.05)$ in the ICA-5 group than in the control group. However, the number in the aging group was significantly lower $(\mathrm{p}<0.05)$ than that in the ICA-5 group (control, 90.4 \pm 1.4 ; aging, 60.9 \pm 3.3 ; and ICA-5, 73.8 \pm 4.2 ; Figure 6B). Fragmentation of genomic DNA was assessed by terminal deoxynucleotidyl transferase dUTP nick-end labeling to detect apoptotic cells within the blastocyst. The percentage of apoptotic cells in the aging group was significantly higher $(\mathrm{p}<0.05)$ than that in the control and ICA-5 groups (control, $1.8 \% \pm 0.6 \%$; aging, $6.0 \% \pm 1.6 \%$; and ICA-5, $2.3 \% \pm 0.7 \%$; Figure $6 \mathrm{C}$ ).

\section{DISCUSSION}

Oocytes are damaged during aging in vitro, and the mecha- nism by which aged oocytes are protected is unknown. This study investigated the effects of ICA, an antioxidant, on the damage that occurs during aging of porcine oocytes in vitro. The easiest way to evaluate the quality of oocytes in vitro is to calculate the rate of developmental. This determines the efficiency of the embryos produced in vitro. In vitro aging of oocytes adcersely affects embryo development and oocyte comperency, and reduces the rate of oocytes cleavage. Our data showed that the developmental rate in the aging group decreased; this was not the case and prevents deterioration of blastocyst quality in the $5 \mu \mathrm{M}$ ICA treated group. This demonstrates that ICA improves embryonic developmental competence by protecting oocytes from age-related damage in vitro.

Previous studies show that ICA reversed ROS damage induced by $\mathrm{H}_{2} \mathrm{O}_{2}$ treatment in mouse embryos [11]. In addition, ICA inhibits ROS production in lipopolysaccharide-treated 
A

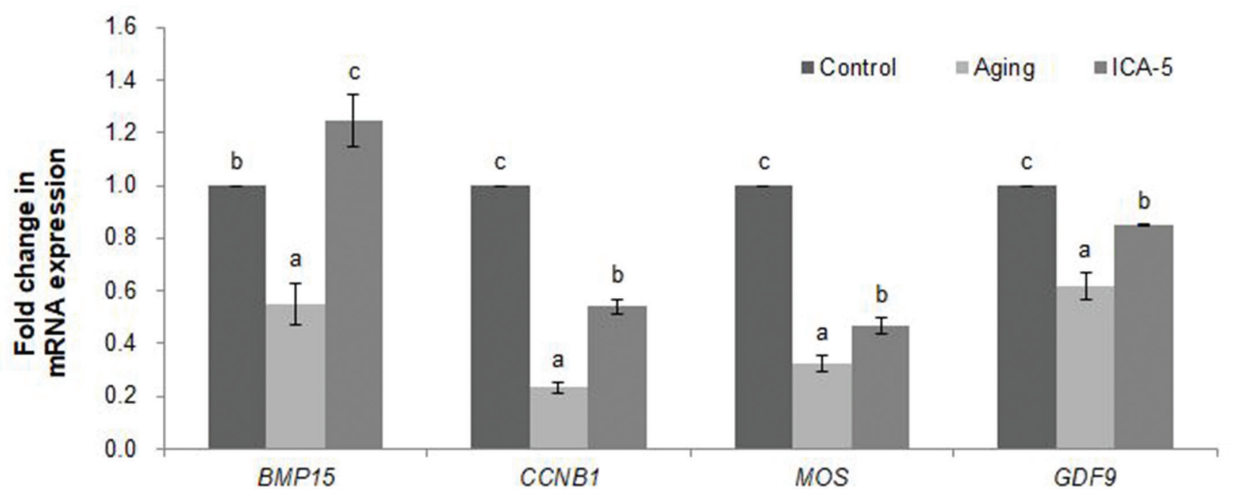

B
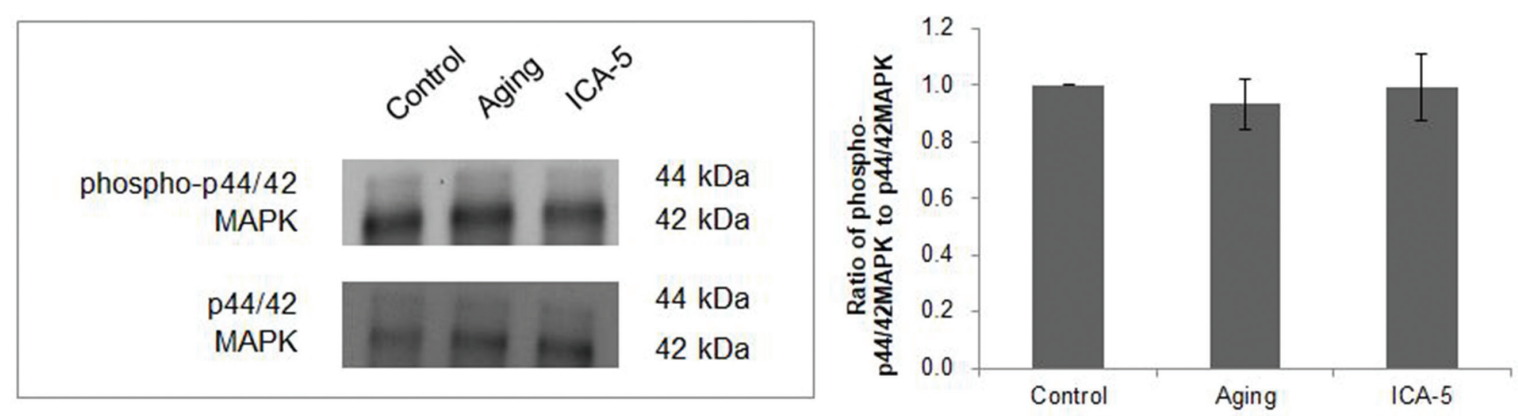

Figure 3. Effect of icariin (ICA) treatment of aging porcine oocytes on expression of maternal genes and MAPK activity. (A) Maternal gene expression. (B) MAPK activity. Data were normalized against levels in the control group. Data are derived from three or five independent replicates per group and are expressed as the mean \pm standard error of the mean $\left({ }^{a-c} p<0.05\right)$.

microglia [12], and could inhibit $\mathrm{H}_{2} \mathrm{O}_{2}$-induced human umbilical vein endothelial injury [13]. Oxidative stress arises in post-ovulatory aging oocytes, in which ROS levels increase with a concomitant reduction in antioxidant protection [14]. Although intracellular GSH plays an important role in protecting oocytes from oxidative damage, levels fall gradually

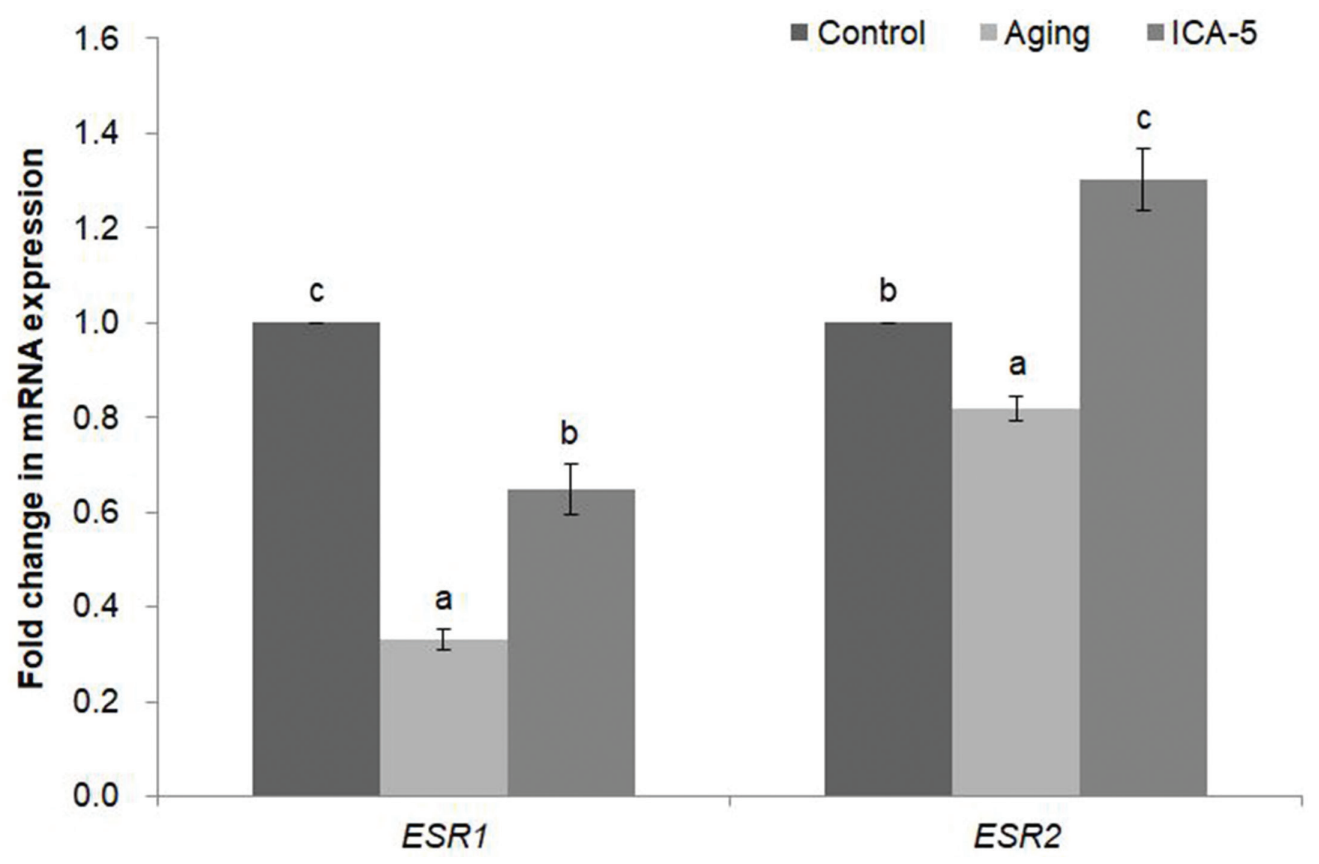

Figure 4. Effect of icariin (ICA) treatment of aging porcine oocytes on expression of estrogen receptor genes. Data are derived from five independent replicates per group and are expressed as the mean \pm standard error of the mean $\left({ }^{a-c} p<0.05\right)$. 


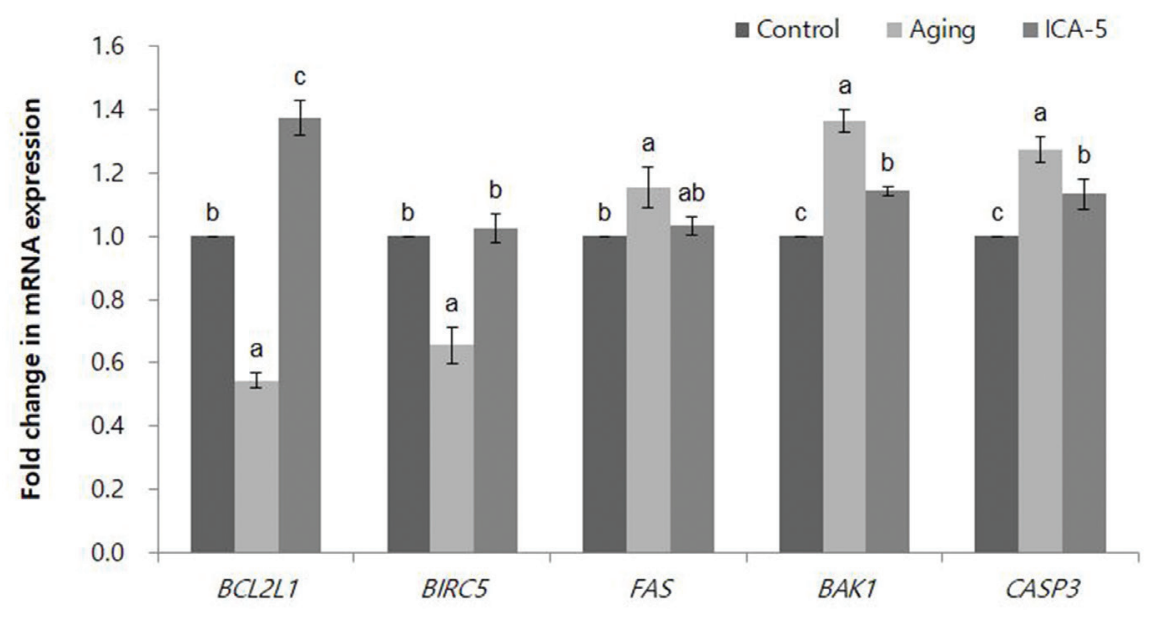

Figure 5. Effect of icariin (ICA) treatment of aging porcine oocytes on expression of apoptosis-related genes. Data are derived from five independent replicates per group and are expressed as the mean \pm standard error of the mean $\left({ }^{a-c} p<0.05\right)$.

during aging [14]. Our results suggest that ICA decreases the level of ROS and prevents the decrease of GSH levels in oocytes during in vitro aging. SOD1 converts two superoxide anions, which are normal products of cellular respiration, into hydrogen peroxide and oxygen $\left[2 \mathrm{O}_{2}^{-}+2 \mathrm{H}^{+} \rightarrow \mathrm{H}_{2} \mathrm{O}_{2}+\mathrm{O}_{2}\right]$ [15]. SOD2 reduces the superoxide anion produced as a by- product of oxidative phosphorylation to generate hydrogen peroxide and oxygen [16]. PRDX5 protects cells against ROS by prioritizing elimination of hydrogen peroxide and alkyl hydroperoxides [17]. NFE2L2 transactivates genes containing antioxidant response elements and coordinates expression of cytoprotective genes to protect cells against oxidative stress
A
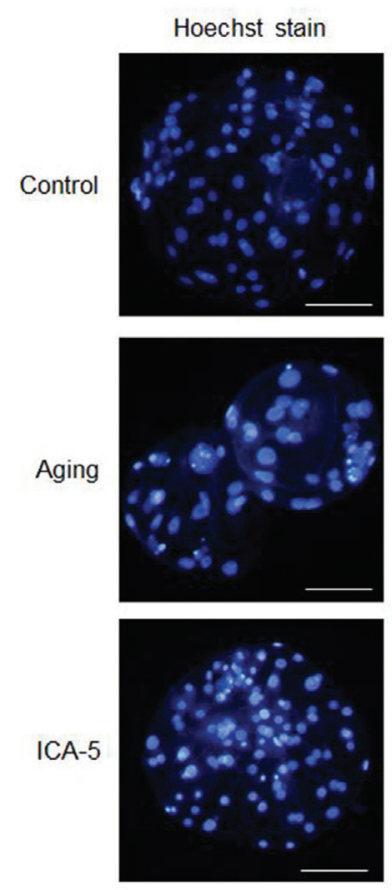
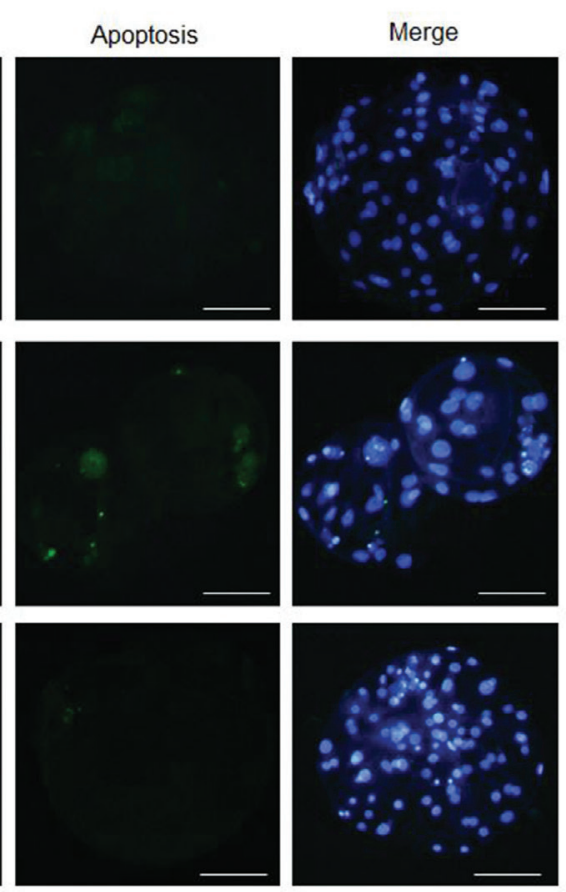
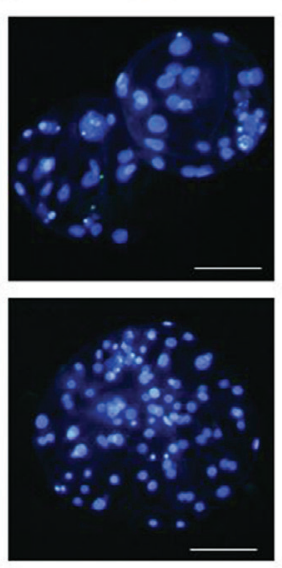

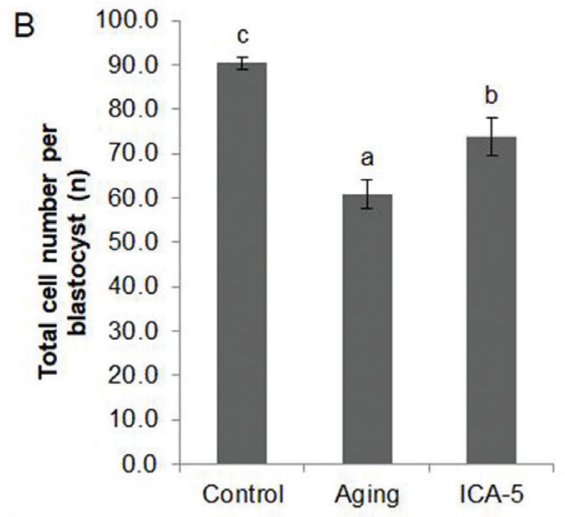

C

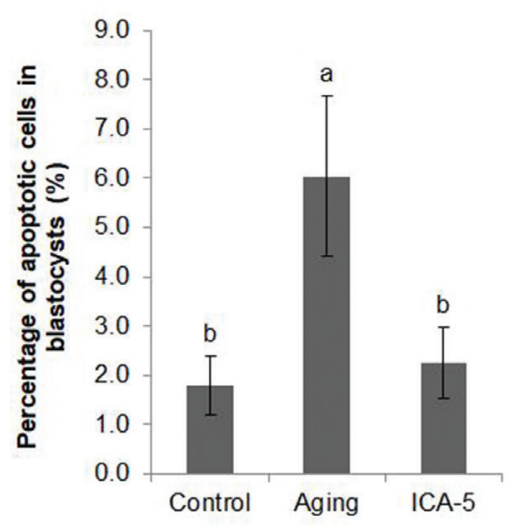

Figure 6. Effect of icariin (ICA) treatment of aging of porcine oocytes on subsequent embryo quality. (A) Blastocyst staining. (B) Total cell number per blastocyst. (C) Percentage of apoptotic cells within the blastocyst. Data are derived from 3 to 4 independent replicates per group and are expressed as the mean \pm standard error of the mean $\left({ }^{a-c} p<0.05\right)$. Scale bar $=50 \mu \mathrm{m}$. 
[18]. Our result showed that expression of these antioxidant genes was increased the ICA-5 group. These results are supported by previous results that ICA decreases the level of ROS and inhibits the decrease of GSH level. Taken together, these results suggest that ICA protects oocytes against oxidative stress, thereby decreases the ROS level, inhibiting the decrease in GSH level, and increasing gene expression.

Chromosome condensation is the most noticeable event during meiotic maturation and is important for formation and proper separation of chromosomes. Oxidative stress generated during aging in the maturation stage of the oocyte has a negative effect on cytoplasmic maturation and nuclear maturation $[14,19]$. In previous studies, there was no data for ICA treatment on oocytes during in vitro aging. However, previous studies have shown that other antioxidants (hesperetin and allicin) protect oocytes against oxidative stress received during aging in vitro and inhibit abnormal spindle formation and decrease of maternal genes and MAPK activity $[14,19]$. Treatment with hesperetin during aging of oocytes in vitro has been shown to protect the chromosomes and spindles in MII and prevent the decrease in expression of the maternal genes CCNB1, MOS, BMP15, and GDF9 [14]. In oocytes, transcription is mostly quiescent and gene expression is regulated by translational rather than transcriptional mechanism [20]. However, the oocytes of control group which completed maturation fully expressed maternal mRNA, whereas the mRNA expression of aged oocytes was downregulated compared to the oocytes of control group. Therefore, we confirmed the protection of maternal mRNA in aged oocytes treated with ICA and also confirmed the translation of mRNA through MAPK activation. Our data showed that the percentage of oocytes with normal spindles in the ICA-5 group was higher than that in the aging group. In additional, although expression of maternal genes increased in the ICA-5 group, phosphorylation of MAPK was no difference in the all groups. Taken together, these results suggest that ICA prevents deterioration of oocyte quality by maintaining nuclear maturation and maternal genes expression. In addition, these results indicate that ICA is a potent compound that helps maintain healthy oocytes by improving the conditions for IVC of oocytes.

ICA might act via estrogen receptors, or in cooperation with estrogen receptor signaling [6]. We examined expression of ESR1 and ESR2 to investigate whether ICA enters oocytes via estrogen receptors. The two types of estrogen receptor are ERa and ER $\beta$, which are encoded by ESR 1 and $E S R 2$, respectively. $E R \beta$ is homologous to $E R \alpha$; indeed, these two proteins have similar, but not identical, tissue distributions. The expression of receptor genes fell in the aging group, and that ICA prevents this decrease. The data suggest that ICA enters porcine oocytes through estrogen receptors.

Apoptosis occurs during aging and development; it is also a maintain cell populations within tissues as a homeostasis mechanism [21]. In addition, apoptosis is a form of programmed cell death that kills individual cells while preserving the overall structure of the surrounding tissue [22]. Excessive apoptosis can affect blastocyst maturation, induce death of an early embryo, and cause fetal deformities [23]. Therefore, we monitored the expression levels of apoptosis-related genes in order to investigate the extent of apoptosis. Several genes control apoptosis. As a dominant inhibitor of apoptosis, $B C L 2 L 1$ is a central regulator of programmed cell death and an important target for anti-cancer drugs [24]. BIRC5 belongs to the inhibitors of apoptosis family; as such, it is involved in regulating cell division and inhibiting apoptosis [25]. BAK1, a member of the BCL-2 family, is an important regulator of mitochondrial apoptosis [26]. Caspases, the primary drivers of apoptotic cell death, cleave cellular proteins, a process that is critical for dismantling dying cells [22]. CASP3 is the most well-characterized effector caspase [22]. Specifically, CASP3 is the executioner caspase and functions during the final phase of apoptosis. Consequently, it is cleaved and activated during late apoptotic events [27]. A previous study reported that ICA prevents apoptosis in human vascular endothelial cells following exposure to oxidized low-density lipoprotein by regulating expression of $B C L-2$ and $C A S P 3$ protein and mRNA [28]. It addition, ICA decreased the expression of pro-apoptotic protein (cleaved caspase 3 and cleaved poly (ADP-ribose) polymerase), by inhibiting the apoptotic signaling pathway in K562 cell exposed to radiation [29]. These results indicate that ICA increased the expression of antiapoptotic genes and decreased the expression of pro-apoptotic genes in aged oocytes, which suggested that ICA effectively blocks apoptosis during oocyte aging by regulating the expression of pro-apoptosis genes or anti-apoptosis genes.

In conclusion, this study indicates that treatment of aging oocytes with $5 \mu \mathrm{M}$ ICA reduces the level of ROS, prevents decreased expression of antioxidant genes (effectively protecting oocytes against oxidative stress), and prevents decreased expression of maternal genes, thereby minimizing deterioration in oocyte quality during aging. Moreover, ICA prevents decreased expression of anti-apoptotic genes, thereby preventing increased expression of pro-apoptotic genes. Finally, ICA increases good-quality blastocyst production by supporting blastocyst development and formation. Thus, ICA may be useful for improving assisted reproductive technologies.

\section{CONFLICT OF INTEREST}

We certify that there is no conflict of interest with any financial organization regarding the material discussed in the manuscript. Kim EY and SP Park are employees of Mirae Cell Bio. 


\section{ACKNOWLEDGMENTS}

This study was supported by the Research Center for Production Management and Technical Development for High Quality Livestock Products through the Agriculture, Food and Rural Affairs Research Center Support Program of the Ministry of Agriculture, Food and Rural Affairs, Republic of Korea (Grant No. 715003-07).

\section{REFERENCES}

1. Wehrend A, Meinecke B. Kinetics of meiotic progression, M-phase promoting factor (MPF) and mitogen-activated protein kinase (MAP kinase) activities during in vitro maturation of porcine and bovine oocytes: species specific differences in the length of the meiotic stages. Anim Reprod Sci 2001;66:175-84. https://doi.org/10.1016/S0378-4320(01) 00094-X

2. Miao YL, Kikuchi K, Sun QY, Schatten H. Oocyte aging: cellular and molecular changes, developmental potential and reversal possibility. Hum Reprod Update 2009;15:57385. https://doi.org/10.1093/humupd/dmp014

3. Diaz H, Esponda P. Postovulatory ageing induces structural changes in the mouse zona pellucida. J Submicrosc Cytol Pathol 2004;36:211-7.

4. Eichenlaub-Ritter U. Oocyte ageing and its cellular basis. Int J Dev Biol 2012;56:841-52. https://doi.org/10.1387/ijdb. 120141ue

5. Li W, Wang L, Chu X, Cui H, Bian Y. Icariin combined with human umbilical cord mesenchymal stem cells significantly improve the impaired kidney function in chronic renal failure. Mol Cell Biochem 2017;428:203-12. https://doi.org/10.1007/ s11010-016-2930-8

6. Song L, Zhao J, Zhang X, Li H, Zhou Y. Icariin induces osteoblast proliferation, differentiation and mineralization through estrogen receptor-mediated ERK and JNK signal activation. Eur J Pharmacol 2013;714:15-22. https://doi.org/10.1016/j. ejphar.2013.05.039

7. Yang HW, Hwang KJ, Kwon HC, Kim HS, Choi KW, Oh KS. Detection of reactive oxygen species (ROS) and apoptosis in human fragmented embryos. Hum Reprod 1998;13:9981002. https://doi.org/10.1093/humrep/13.4.998

8. You J, Kim J, Lim J, Lee E. Anthocyanin stimulates in vitro development of cloned pig embryos by increasing the intracellular glutathione level and inhibiting reactive oxygen species. Theriogenology 2010;74:777-85. https://doi.org/10.1016/j. theriogenology.2010.04.002

9. Lee SE, Sun SC, Choi HY, Uhm SJ, Kim NH. mTOR is required for asymmetric division through small GTPases in mouse oocytes. Mol Reprod Dev 2012;79:356-66. https://doi.org/ 10.1002/mrd.22035

10.Livak KJ, Schmittgen TD. Analysis of relative gene expression data using real-time quantitative PCR and the $2^{-\Delta \Delta C T}$ method. Methods 2001;25:402-8. https://doi.org/10.1006/meth.2001. 1262

11. Ye R, Xu S, Liu Y, et al. Protective effect of icariin on the development of preimplantation mouse embryos against hydrogen peroxide-induced oxidative injury. Oxid Med Cell Longev 2017;2017:2704532. https://doi.org/10.1155/2017/2704532

12.Zeng KW, Fu H, Liu GX, Wang XM. Icariin attenuates lipopolysaccharide-induced microglial activation and resultant death of neurons by inhibiting TAK1/IKK/NF- $\mathrm{KB}$ and JNK/ p38 MAPK pathways. Int immunopharmacol 2010;10:66878. https://doi.org/10.1016/j.intimp.2010.03.010

13. Wang YK, Huang ZQ. Protective effects of icariin on human umbilical vein endothelial cell injury induced by $\mathrm{H}_{2} \mathrm{O}_{2}$ in vitro. Pharmacol Res 2005;52:174-82. https://doi.org/10. 1016/j.phrs.2005.02.023

14. Kim WJ, Lee SE, Park YG, Jeong SG, Kim EY, Park SP. Antioxidant hesperetin improves the quality of porcine oocytes during aging in vitro. Mol Reprod Dev 2019;86:32-41. https:// doi.org/10.1002/mrd.23079

15. McCord JM, Fridovich I. Superoxide dismutase. An enzymatic function for erythrocuprein (hemocuprein). J Biol Chem 1969; 244:6049-55.

16. Margalit DN, Jordahl KM, Werner L, et al. Germline variation in superoxide dismutase-2 (SOD2) and survival outcomes after radiation therapy for prostate cancer: results of a test and validation set analysis. Clin Genitourin Cancer 2015; 13:370-7. https://doi.org/10.1016/j.clgc.2014.12.018

17. Knoops B, Goemaere J, van der Eecken V, Declercq JP. Peroxiredoxin 5: structure, mechanism, and function of the mammalian atypical 2-Cys peroxiredoxin. Antioxid Redox Signal 2011;15:817-29. https://doi.org/10.1089/ars.2010.3584

18.Itoh K, Ye P, Matsumiya T, Tanji K, Ozaki T. Emerging functional cross-talk between the Keap1-Nrf2 system and mitochondria. J Clin Biochem Nutr 2015;56:91-7. https://doi. org/10.3164/jcbn.14-134

19. Park YG, Lee SE, Yoon JW, Kim EY, Park SP. Allicin protects porcine oocytes against damage during aging in vitro. Mol Reprod Dev 2019;86:1116-25. https://doi.org/10.1002/mrd. 23227

20. Martins JPS, Conti M. Profiling maternal mRNA translation during oocyte development. Methods Mol Biol 2018;1818: 43-50. https://doi.org/10.1007/978-1-4939-8603-3_6

21.Elmore S. Apoptosis: a review of programmed cell death. Toxicol Pathol 2007;35:495-516. https://doi.org/10.1080/ 01926230701320337

22.Parrish AB, Freel CD, Kornbluth S. Cellular mechanisms controlling caspase activation and function. Cold Spring Harb Perspect Biol 2013;5:a008672. http://doi.org/10.1101/ cshperspect.a008672

23. Brison DR, Schultz RM. Apoptosis during mouse blastocyst formation: evidence for a role for survival factors including 
transforming growth factor $\alpha$. Biol Reprod 1997;56:1088-96. https://doi.org/10.1095/biolreprod56.5.1088

24. Oltersdorf T, Elmore SW, Shoemaker AR, et al. An inhibitor of Bcl-2 family proteins induces regression of solid tumours. Nature 2005;435:677-81. https://doi.org/10.1038/nature03579

25. Contis J, Lykoudis PM, Goula K, Karandrea D, Kondi-Pafiti A. Survivin expression as an independent predictor of overall survival in pancreatic adenocarcinoma. J Cancer Res Ther 2018;14(Suppl 3):S719-23. https://doi.org/10.4103/0973-1482. 187346

26. Birkinshaw RW, Czabotar PE. The BCL-2 family of proteins and mitochondrial outer membrane permeabilisation. Semin Cell Dev Biol 2017;72:152-62. https://doi.org/10.1016/j.semcdb.
2017.04.001

27. Riedl SJ, Shi Y. Molecular mechanisms of caspase regulation during apoptosis. Nat Rev Mol Cell Biol 2004;5:897-907. https:// doi.org/10.1038/nrm1496

28. Hu Y, Li H, Liu K, Zhang Y, Ren L, Fan Z. Protective effects of icariin on human vascular endothelial cells induced by oxidized low-density lipoprotein via modulating caspase-3 and Bcl-2. Mol Med Rep 2018;17:6835-9. https://doi.org/ 10.3892/mmr.2018.8717

29.Park BK, Lee JH, Seo HW, Oh KS, Lee JH, Lee BH. Icariin protects against radiation-induced mortality and damage in vitro and in vivo. Int J Radiat Biol 2019;95:1094-102. https:// doi.org/10.1080/09553002.2019.1589021 